\title{
PENGARUH PERSEPSI NILAI, PERSEPSI RISIKO DAN SIKAP TERHADAP NIAT MEMBELI KEMBALI PADA MAKANAN CEPAT SAJI
}

\author{
Ni Ketut Eugenia Shara Devi ${ }^{1}$ \\ Ni Made Asti Aksari ${ }^{2}$ \\ ${ }^{1,2}$ Fakultas Ekonomi dan Bisnis Universitas Udayana (Unud), Bali, Indonesia \\ email: eugeniashara@gmail.com
}

\begin{abstract}
ABSTRAK
Makanan cepat saji merupakan alternatif konsumsi di zaman serba praktis seiring meningkatnya aktivitas masyarakat modern seperti sekarang. Penelitian ini bertujuan untuk menjelaskan pengaruh persepsi nilai, persepsi risiko dan sikap terhadap niat konsumen untuk membeli kembali makanan cepat saji pada restoran cepat saji di Indonesia. Sampel terdiri dari 100 orang masyarakat Indonesia yang telah lulus SMA dan pernah membeli serta mengonsumsi makanan cepat saji. Data dikumpulkan dengan menyebarkan kuesioner secara online dan diolah menggunakan Partial Least Square. Hasil penelitian menunjukkan persepsi nilai memengaruhi sikap secara positif, sementara persepsi risiko memengaruhi sikap secara negatif. Hasil tersebut mengindikasikan semakin besar manfaat yang dirasakan konsumen setelah membeli dan mengonsumsi makanan cepat saji maka semakin baik sikap konsumen terhadap makanan cepat saji dan semakin tinggi risiko yang dirasakan konsumen akan mengurangi rasa suka konsumen terhadap makanan cepat saji. Sikap ditemukan memengaruhi niat membeli kembali secara positif
\end{abstract}

Kata kunci: persepsi nilai, persepsi risiko, sikap, niat membeli kembali, makanan cepat saji

\begin{abstract}
As the activities of modern society increases, fast food is an alternative for consumption in today's instant era. This study aims to describe the influence of perceived value, perceived risk, and attitude on repurchase intention of fast food in quick service restaurants in Indonesia. The study samples consist of 100 Indonesians who have graduated from senior high school and have purchased and consumed fast food. Data were collected through online questionnaires and analyzed using Partial Least Square). Research result found that perceived value positively affect attitude, while perceived risk was found to negatively affect attitude. It indicates that the more value consumers received after purchasing and consuming fast food, their attitude towards fast food are more positive, on the other hand, the higher the risk consumers received, their attitude towards fast food becomes less positive. Attitude was found to positively affect repurchase intention of fast food.

Keywords: perceived value, perceived risk, attitude, repurchase intention, fast food.
\end{abstract}




\section{PENDAHULUAN}

Tingkat aktivitas yang padat menuntut segala sesuatu terselesaikan dengan cepat (Joseph dkk. 2017). Dampak dari adanya gaya hidup serba cepat dapat dilihat dari pola konsumsi masyarakat yang menginginkan kepraktisan (Evan \& Candrawati, 2017) dimana banyak masyarakat mulai mengonsumsi makanan seraya berpindah ke tempat lain (munching on the move) (Nielsen, 2016). Kemajuan teknologi menawarkan makanan cepat saji sebagai salah satu solusi makanan dari gaya hidup serba cepat (Anwar, 2016).

Makanan cepat saji merupakan jenis makanan yang proses persiapan dan penyajiannya dilakukan dengan cepat (Srivastava, 2014). Makanan cepat saji juga mudah dikemas dan praktis (Hanum dkk., 2015). Contoh makanan cepat saji adalah semua makanan yang ditawarkan di restoran cepat saji seperti pizza, hamburger, ayam goreng, kentang goreng, soft drink, dan sebagainya (Anwar, 2016; Hazanah \& Andriani, 2016; Bonita \& Fitranti, 2017)

Berdasakan Nielsen, salah satu perusahaan penyedia data penelitian berbasis global, pada tahun 2016 di negara - negara Asia-Pasifik yang salah satunya adalah Indonesia, persentase orang yang berkunjung ke restoran cepat saji sebesar 60\%. Menurut surat kabar Wartakota, pada tahun 2016 persentase yang cukup tinggi juga ditemukan dari survei Master Card dengan judul Consumer Purchasing Priorities dimana $80 \%$ orang Indonesia memilih bersantap di restoran cepat saji.

Menurut portal statistik intelijen Statista, beberapa contoh restoran cepat saji di Indonesia pada 2018 adalah Kentucky Fried Chicken (KFC) dengan menu andalan ayam goreng yang memiliki sekitar 590 gerai, McDonald's yang identik dengan menu hamburger memiliki sekitar 181 gerai, Burger King yang juga menawarkan berbagai varian hamburger, memiliki sekitar 87 gerai, Pizza Hut yang terkenal dengan produk pizza, memiliki sekitar 393 gerai, dan Domino's Pizza yang juga menawarkan berbagai varian pizza dengan jumlah gerai sekitar 100 gerai. Setiap merek memiliki menu khasnya sendiri yang dapat dijumpai di seluruh gerai mereka.

Tingginya intensitas untuk mengonsumsi makanan cepat saji cukup menarik ketika beberapa penelitian menemukan bahaya dari makanan cepat saji. Kalori, lemak, protein, gula dan garam yang relatif tinggi pada makanan cepat saji dapat menyebabkan gizi berlebih, obesitas, diabetes, stroke, kanker, hipertensi, penyakit jantung koroner dan pergeseran pembuluh darah (Afifah dkk., 2017; Damopolii, Mayulu, \& Masi, 2013).

Hasil dari lembaga survei Qraved terhadap 13.890 responden di Jakarta mengenai konsumsi junk food menyatakan bahwa 92\% dari responden mengetahui sisi negatif dari makanan cepat saji namun terus mengonsumsinya (Yanuar, 2016). Jika dilihat, harga makanan cepat saji sendiri di Indonesia berkisar Rp 17.000 untuk satu buah ayam goreng (tidak termasuk nasi) di KFC (Hardian, 2018) terbilang cukup tinggi untuk orang Indonesia dimana rata - rata pendapatan karyawan per Agustus 2017 Rp 2.742.621,- (Badan Pusat Statistik, 2018).

Mengonsumsi atau membeli lagi merupakan salah satu indikator adanya niat membeli kembali (Tjandra dkk., 2015). Niat membeli kembali adalah salah satu 
bentuk dari niat berperilaku (Zheng et al., 2017). Niat membeli kembali adalah keinginan konsumen untuk membeli produk atau merek yang sama lagi di masa mendatang. Konsumen melakukan usaha untuk mendapatkan suatu produk ketika memiliki niat membeli kembali (Goh et al., 2016). Berdasarkan Theory of Reasoned Action niat membeli kembali dipengaruhi oleh sikap (Schiffman \& Wisenblit, 2015:184)

Sikap adalah perasaan suka atau tidak suka konsumen terhadap suatu objek yang dapat berupa barang, jasa, pelayanan dan hal lainnya. Sikap memengaruhi niat membeli kembali secara positif (Kusuma \& Marta, 2014; Mao \& Lyu, 2017). Sikap menentukan keputusan konsumen untuk membeli lagi atau tidak (Ahmadi, Syahlani, \& Haryadi, 2010). Semakin baik sikap konsumen terhadap suatu produk, maka semakin tinggi pula niat membeli kembali mereka (Dewi \& Ardani, 2016). Sikap positif yang dimiliki konsumen setelah mempertimbangkan manfaat dari suatu produk, merupakan salah satu penyebab adanya niat untuk membeli produk itu kembali di masa depan (Yudha \& Sumiati, 2015)

Sikap konsumen terbentuk dari pertimbangan atas persepsi nilai (Hermawan \& Haryanto, 2013). Persepsi nilai adalah manfaat yang diterima konsumen dari pengorbanan yang dilakukan terhadap suatu objek. Penelitian (Zhu et al., 2017) menemukan bahwa persepsi nilai memengaruhi sikap secara positif. Semakin tinggi manfaat yang dirasakan konsumen dari suatu produk terhadap kehidupannya, semakin baik sikap mereka terhadap produk tersebut (Hassan et al., 2016). Mao \& Lyu (2017) yang meneliti perilaku konsumen AirBnb menemukan bahwa persepsi nilai memengaruhi sikap secara positif. Ketika konsumen memilih suatu produk, mereka merasakan kontribusi atau keunikan tersendiri yang menentukan sikap mereka pada produk tersebut.

Persepsi risiko adalah ketidakpastian yang dihadapi konsumen dari keputusannya untuk membeli produk dimana cenderung merugikan. Persepsi risiko digunakan untuk meneliti perilaku konsumen yang dilihat dari sisi ketidakpuasaan konsumen terhadap produk (Hassan, 2017). Persepsi risiko berpengaruh negatif terhadap sikap, setiap risiko yang diketahui oleh konsumen dari keputusan membeli dan mengonsumsi produk, akan sangat menentukan sikap mereka terhadap produk tersebut (Choi et al., 2013; Liou et al., 2014). Ketika konsumen menyadari risiko dari mengonsumsi ataupun membeli suatu produk, rasa suka mereka terhadap produk tersebut akan berkurang (Sharma \& Kalyandurgmath, 2016). Konsumen memprediksi risiko - risiko yang mungkin dialami sehingga hal tersebut memengaruhi sikap mereka (Mao \& Lyu, 2017). Tingkat ketidakpastian yang dirasakan konsumen pada keputusan pembelian dapat berlipat ganda pada produk seperti makanan dan obat - obatan (Shahid, 2012). Pengaruh dari persepsi risiko terhadap sikap pada penelitian di atas adalah pengaruh negatif yang langsung dan signifikan, berbeda dengan penelitian Bashir \& Madhavaiah (2015) yang menemukan persepsi risiko belum memberikan efek langsung yang signifikan pada sikap, maka diperlukan penelitian kembali mengenai pengaruh persepsi risiko terhadap sikap. Gambar 1 menampilkan kerangka konseptual pada penelitian ini yang dirancang berdasarkan fenomena dan penelitian terdahulu. 


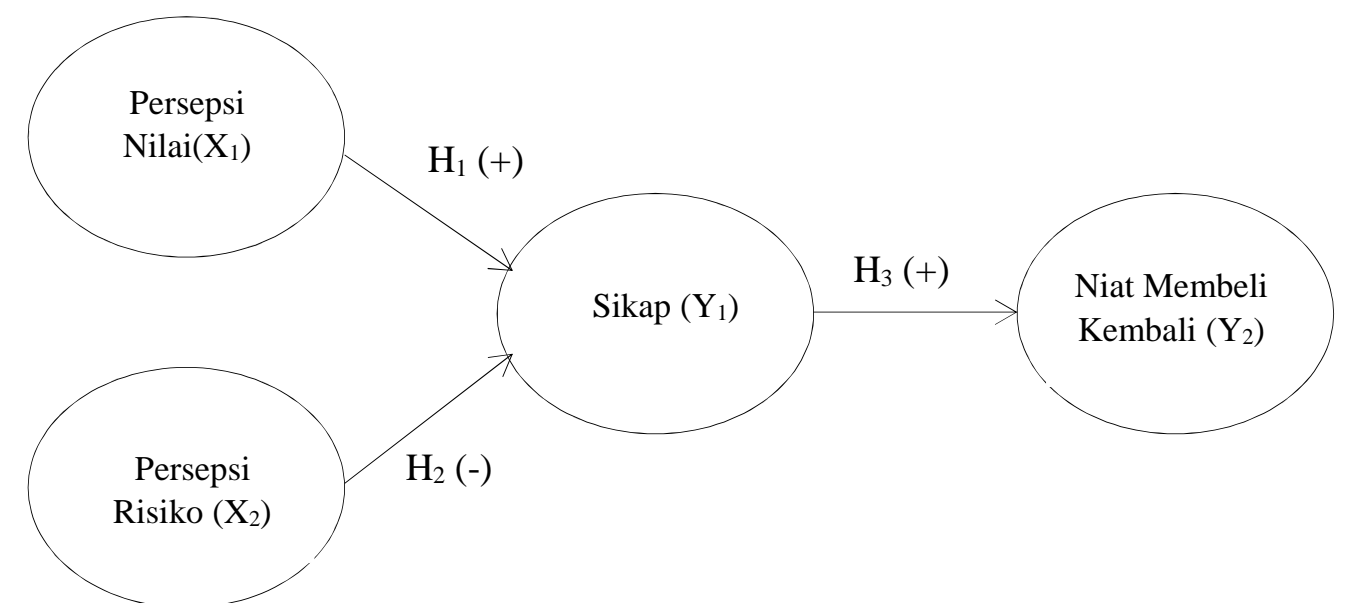

\section{Gambar 1. Kerangka Konseptual}

Sumber: Mao \& Lyu, 2017

$\mathrm{H}_{1}$ : Persepsi nilai berpengaruh positif terhadap sikap

$\mathrm{H}_{2}$ : Persepsi risiko berpengaruh negatif terhadap sikap.

$\mathrm{H}_{3}$ : Sikap berpengaruh positif terhadap niat membeli kembali.

\section{METODE PENELITIAN}

Penelitian ini menggunakan pendekatan kuantitatif dengan jenis penelitian asosiatif yang menjelaskan pengaruh persepsi nilai, persepsi risiko, dan sikap terhadap niat membeli kembali pada makanan cepat saji. Variabel bebas (eksogen) yaitu persepsi nilai $\left(\mathrm{X}_{1}\right)$ dan persepsi risiko $\left(\mathrm{X}_{2}\right)$ dengan dua variabel terikat (endogen) yaitu sikap $\left(\mathrm{Y}_{1}\right)$ dan niat membeli kembali $\left(\mathrm{Y}_{2}\right)$.

Populasi pada penelitian ini adalah masyarakat Indonesia yang pernah membeli dan mengonsumsi makanan cepat saji di restoran cepat saji seperti Kentucky Fried Chicken (KFC), McDonald's, Burger King, Pizza Hut, Domino's Pizza dan sejenisnya di Indonesia yang jumlahnya tidak terbatas. Sampel dipilih secara tidak acak yang berarti untuk dapat menjadi sampel terdapat beberapa persyaratan yang harus terpenuhi (Sugiyono, 2017:154). Lokasi penelitian bertempat di Kota Denpasar, Bali.

Pengumpulan data dilakukan menggunakan kuesioner yang dinilai dengan skala Likert. Kuesioner disebar secara online dalam format google form menggunakan teknik snowball sampling. Kuesioner berisi beberapa pernyataan mengenai indikator variabel yang tersaji pada Tabel 1. Variabel kuesioner dikatakan valid jika memiliki koefisien korelasi (r) hitung lebih besar sama dengan 0,30 (Sugiyono, 2017:154) dan reliabel apabila memiliki nilai Cronbach's Alpha $(\alpha)>0,70$ yang diukur menggunakan SPSS (Ghozali, 2016:23).

Data dianalisis menggunakan satistif deskriptif dan statistik inferensia. Statistik deskriptif adalah statistik yang digunakan untuk menganalisis data dengan cara mendeskripsikan data yang telah terkumpul sebagaimana adanya tanpa ada tujuan untuk menyimpulkan data yang sudah terkumpul (Sugiyono, 2017:232). Penilaian responden mengenai variabel-variabel dalam penelitian ditentukan distribusi frekuensinya berdasarkan nilai intervalnya (Utama, 
2015:21). Skor pada penelitian ini memiliki nilai tertinggi maksimal 5 dan terendah minimal 1, sehingga dapat disusun kriteria pengukuran seperti pada Tabel 2.

\section{Tabel 1.}

\section{Indikator Variabel Penelitian}

\begin{tabular}{|c|c|c|c|}
\hline \multirow{6}{*}{$\begin{array}{l}\text { Variabel } \\
\text { Persepsi } \\
\text { Nilai } \\
\text { (X1) }\end{array}$} & Dimensi & Indikator & Sumber \\
\hline & Kualitas & Menurut Saya makanan cepat saji lezat & Ryu, Lee, \& \\
\hline & & $\begin{array}{l}\text { Menurut Saya makanan cepat saji memiliki } \\
\text { berbagai variasi jenis }\end{array}$ & $\operatorname{Kim}(2012)$ \\
\hline & & $\begin{array}{l}\text { Menurut Saya makanan cepat saji memiliki } \\
\text { tampilan visual yang menarik }\end{array}$ & \\
\hline & $\begin{array}{l}\text { Behavioral } \\
\text { Price }\end{array}$ & $\begin{array}{l}\text { Menurut Saya proses pembelian makanan } \\
\text { cepat saji hemat waktu }\end{array}$ & Petrick (2002) \\
\hline & Reputasi & $\begin{array}{l}\text { Menurut Saya dengan membeli makanan cepat } \\
\text { saji dapat menaikkan gengsi saya }\end{array}$ & \\
\hline \multirow{4}{*}{$\begin{array}{l}\text { Persepsi } \\
\text { Risiko } \\
(\mathrm{X} 2)\end{array}$} & Risiko Fisik & Menurut Saya mengonsumsi makanan cepat & Wang (2015) \\
\hline & & $\begin{array}{l}\text { saj1 menyebabkan obesitas (kelebihan lemak) } \\
\text { Menurut Saya mengonsumsi makanan cepat } \\
\text { saji menyebabkan diabetes (kadar gula dalam } \\
\text { tubuh tinggi) }\end{array}$ & \\
\hline & Risiko & Menurut Saya harga makanan cepat saji tidak & Stone \& \\
\hline & Finansial & sesuai dengan manfaat yang diberikan. & $\begin{array}{l}\text { Grønhaug, } \\
(1993)\end{array}$ \\
\hline \multirow[t]{3}{*}{$\begin{array}{l}\text { Sikap } \\
\text { (Y1) }\end{array}$} & Kognitif & $\begin{array}{l}\text { Menurut Saya membeli makanan cepat saji } \\
\text { adalah keputusan yang rasional }\end{array}$ & $\begin{array}{l}\text { Schiffman \& } \\
\text { Wisenblit }\end{array}$ \\
\hline & Afektif & Saya suka mengonsumsi makanan cepat saji & $(2015)$ \\
\hline & & $\begin{array}{l}\text { Saya merasa gembira dapat mengonsumsi } \\
\text { makanan cepat saji }\end{array}$ & $\begin{array}{l}\text { Tamulien , } \\
(2015)\end{array}$ \\
\hline \multirow{4}{*}{$\begin{array}{l}\text { Niat } \\
\text { Membeli } \\
\text { Kembali } \\
\text { (Y2) }\end{array}$} & & Saya ingin membeli makanan cepat saji lagi. & Panthura, \\
\hline & & Jika ada variasi baru dari makanan cepat saji & $(2011)$ \\
\hline & & di masa depan, Saya akan membelinya. & Oktarini \& \\
\hline & & $\begin{array}{l}\text { Saya akan merekomendasikan makanan cepat } \\
\text { saji kepada kerabat saya. }\end{array}$ & $\begin{array}{l}\text { Wardana, } \\
(2018)\end{array}$ \\
\hline
\end{tabular}

Sumber: Penelitian terdahulu

$$
\text { Interval }=\frac{\text { Nilai Tertinggi }- \text { Nilai Terendah }}{\text { Jumlah Kelas }}=\frac{5-1}{5}=0,80
$$

Tabel 2.

Kriteria Pengukuran Deskripsi Variabel Penelitian

\begin{tabular}{|c|c|c|c|c|c|}
\hline No. & $\begin{array}{c}\text { Skala } \\
\text { Pengukuran }\end{array}$ & Persepsi Nilai & $\begin{array}{c}\text { Persepsi } \\
\text { Risiko }\end{array}$ & Sikap & $\begin{array}{c}\text { Niat Membeli } \\
\text { Kembali }\end{array}$ \\
\hline 1 & $1,00-1,80$ & Sangat Rendah & Sangat Rendah & $\begin{array}{c}\text { Sangat Tidak } \\
\text { Baik }\end{array}$ & Sangat Rendah \\
\hline 2 & $1,81-2,60$ & Rendah & Rendah & Tidak Baik & Rendah \\
\hline 3 & $2,61-3,40$ & Cukup Tinggi & Cukup Tinggi & Cukup Baik & Cukup Tinggi \\
\hline 4 & $3,41-4,20$ & Tinggi & Tinggi & Baik & Tinggi \\
\hline 5 & $4,21-5,00$ & Sangat Tinggi & Sangat Tinggi & Sangat Baik & Sangat Tinggi \\
\hline
\end{tabular}


Statistik inferensia yang digunakan adalah Partial Least Square (PLS). PLS adalah metode analisis yang powerfull karena mengakomodasikan data berbagai skala ukuran dan tidak mengasumsikan data harus dalam skala pengukuran tertentu karena berbasis statistik nonparametrik. (Suyana, 2016:177). Adapun langkah - langkah dalam pengujian PLS terdiri dari uji model pengukuran (outer model), uji model struktural (inner model) dan pengujian hipotesis (Abdillah \& Jogiyanto, 2015:32)

\section{HASIL DAN PEMBAHASAN}

Tabel 3.

Karakteristik Responden

\begin{tabular}{|c|c|c|c|c|}
\hline No. & Karakteristik & Klasifikasi & $\begin{array}{l}\text { Jumlah Responden } \\
\text { (orang) }\end{array}$ & $\begin{array}{c}\text { Persentase } \\
\text { Responden (\%) }\end{array}$ \\
\hline \multirow[t]{6}{*}{1} & Domisili & Bali,NTB,NTT & 20 & 20 \\
\hline & & Jawa & 16 & 16 \\
\hline & & Sumatera & 16 & 16 \\
\hline & & Kalimantan & 16 & 16 \\
\hline & & Sulawesi & 16 & 16 \\
\hline & & Papua dan sekitarnya & 16 & 16 \\
\hline \multirow[t]{2}{*}{2} & Jenis Kelamin & Laki - Laki & 40 & 40 \\
\hline & & Perempuan & 60 & 60 \\
\hline \multirow[t]{6}{*}{3} & Pekerjaan & Mahasiswa & 59 & 59 \\
\hline & & PNS & 11 & 11 \\
\hline & & Wiraswasta & 8 & 8 \\
\hline & & Pegawai Swasta & 19 & 19 \\
\hline & & Ibu Rumah Tangga & 1 & 1 \\
\hline & & Pegawai Kontrak & 2 & 2 \\
\hline \multirow[t]{4}{*}{4} & Usia & 18 - 25 Tahun & 68 & 68 \\
\hline & & 26 - 35 Tahun & 17 & 17 \\
\hline & & 36 - 45 Tahun & 9 & 9 \\
\hline & & > 45 Tahun & 6 & 6 \\
\hline \multirow[t]{4}{*}{5} & Pendapatan & $0-1.5$ & 56 & 56 \\
\hline & (dalam juta & $1.6-2.5$ & 14 & 14 \\
\hline & rupiah) & $2.6-3.5$ & 14 & 14 \\
\hline & & $>3.5$ & 16 & 16 \\
\hline
\end{tabular}

Sumber: Data primer diolah, 2019

Berdasarkan data dari 100 responden pada Tabel 3, responden berdomisili di Bali, NTB, dan NTT adalah yang paling mendominasi dengan angka 20 persen. Responden perempuan lebih banyak dengan angka 60 persen dibandingkan responden laki - laki. Berdasarkan pekerjaannya, mahasiswa merupakan responden terbanyak dengan angka 59 persen dan Ibu rumah tangga menjadi pekerjaan dengan persentase paling sedikit yaitu hanya 1 persen. Responden berusia lebih dari 18 - 25 tahun merupakan yang terbanyak dengan persentase 68 persen, sedangkan persentase terendah dimiliki oleh responden dengan rentang usia > 45 tahun dengan presentase 6 persen. Sementara dari segi pendapatan, pendapatan $\mathrm{Rp} 0,00$ - Rp 1.500.000,00, merupakan yang terbanyak dengan angka 56 persen. Responden dengan pendapatan Rp 1.600.000,00 - Rp 2.500.000,00 dan Rp 2.600.000,00 - Rp 3.500.000,00 memiliki angka yang sama yaitu 14 persen. 
Tabel 4.

Hasil Uji Validitas Instrumen Penelitian

\begin{tabular}{ccccc}
\hline Variabel & Indikator & Koefisien Korelasi & Korelasi Batas & Keterangan \\
\hline \multirow{2}{*}{ Persepsi Nilai } & $\mathrm{X}_{1.1}$ & 0,875 & 0,30 & Valid \\
$\left(\mathrm{X}_{1}\right)$ & $\mathrm{X}_{1.3}$ & 0,764 & 0,30 & Valid \\
& $\mathrm{X}_{1.4}$ & 0,823 & 0,30 & Valid \\
& $\mathrm{X}_{1.5}$ & 0,778 & 0,30 & Valid \\
Persepsi Risiko & $\mathrm{X}_{2.1}$ & 0,894 & 0,30 & Valid \\
$\left(\mathrm{X}_{2}\right)$ & $\mathrm{X}_{2.2}$ & 0,909 & 0,30 & Valid \\
& $\mathrm{X}_{2.3}$ & 0,737 & 0,30 & Valid \\
\multirow{2}{*}{ Sikap $\left(\mathrm{Y}_{1}\right)$} & $\mathrm{Y}_{1.1}$ & 0,787 & 0,30 & Valid \\
& $\mathrm{Y}_{1.2}$ & 0,916 & 0,30 & Valid \\
\multirow{2}{*}{ Niat Membeli } & $\mathrm{Y}_{1.3}$ & 0,913 & 0,30 & Valid \\
Kembali $\left(\mathrm{Y}_{2}\right)$ & $\mathrm{Y}_{2.1}$ & 0,871 & 0,30 & Valid \\
& $\mathrm{Y}_{2.2}$ & 0,805 & 0,30 & Valid \\
\hline
\end{tabular}

Sumber: Data primer diolah, 2019

Hasil uji validitas pada Tabel 4. menunjukkan bahwa seluruh instrumen penelitian yang digunakan memiliki nilai koefisien korelasi lebih besar dari 0,30 yang berarti valid dan layak digunakan sebagai instrumen penelitian. Variabel dikatakan reliabel apabila memiliki nilai Cronbach's Alpha $(\alpha)>0,70$ yang dapat diukur menggunakan SPSS. Tabel 5 menunjukkan hasil uji reliabilitas instrumen. Seluruh instrumen penelitian memiliki koefisien Cronbach's Alpha lebih dari 0,70 , sehingga seluruh variabel dapat dikatakan reliabel dan dapat digunakan untuk melakukan penelitian.

Berdasarkan jawaban responden pada Tabel 6. variabel persepsi nilai berada pada kategori tinggi dengan nilai rata - rata keseluruhan 3,77 konsumen merasakan banyak manfaat dari mengonsumsi dan membeli makanan cepat saji. Variabel persepsi risiko berada pada kategori tinggi dengan nilai rata - rata keseluruhan 3,60 yang berarti konsumen menyadari risiko yang mereka hadapi dari keputusan membeli dan mengonsumsi makanan cepat saji. Variabel sikap berada pada kategori cukup baik dengan nilai rata - rata keseluruhan 3,32 yang berarti konsumen menunjukkan sikap suka namun tidak seutuhnya terhadap makanan cepat saji, terdapat sedikit rasa tidak suka atau perasaan mengganjal ketika membeli dan mengonsumsi makanan cepat saji. Variabel niat membeli kembali berada pada kategori tinggi dengan nilai rata - rata keseluruhan 3,45 yang berarti konsumen memiliki keinginan yang besar untuk membeli dan mengonsumi lagi makanan cepat saji.

Tabel 5.

Hasil Uji Reliabilitas Instrumen Penelitian

\begin{tabular}{clcc}
\hline No. & \multicolumn{1}{c}{ Variabel } & Cronbadh'sAlpha & Keterangan \\
\hline 1 & Persepsi Nilai $\left(\mathrm{X}_{1}\right)$ & 0,878 & Reliabel \\
2 & Persepsi Risiko $\left(\mathrm{X}_{2}\right)$ & 0,794 & Reliabel \\
3 & Sikap $\left(\mathrm{Y}_{1}\right)$ & 0,837 & Reliabel \\
4 & Niat Membeli Kembali $\left(\mathrm{Y}_{2}\right)$ & 0,846 & Reliabel \\
\hline
\end{tabular}

Sumber: Data primer diolah, 2019 
Tabel 6.

Jawaban Responden Terhadap Pernyataan Kuesioner

\begin{tabular}{|c|c|c|c|c|c|c|c|}
\hline \multirow{2}{*}{ Pernyataan } & \multicolumn{5}{|c|}{ Frekuensi Penilaian Responden } & \multirow{2}{*}{ Rata-Rata } & \multirow{2}{*}{ Kriteria } \\
\hline & STS & TS & $\mathbf{N}$ & $\mathbf{S}$ & SS & & \\
\hline \multicolumn{8}{|l|}{ Persepsi nilai } \\
\hline $\begin{array}{l}\text { Menurut Saya rasa makanan cepat } \\
\text { saji lezat. }\end{array}$ & 0 & 0 & 32 & 57 & 11 & 3,79 & Tinggi \\
\hline $\begin{array}{l}\text { Menurut Saya makanan cepat saji } \\
\text { memiliki berbagai variasi jenis. }\end{array}$ & 0 & 0 & 14 & 72 & 14 & 4,00 & Tinggi \\
\hline $\begin{array}{l}\text { Menurut Saya makanan cepat saji } \\
\text { memiliki tampilan visual yang } \\
\text { menarik. }\end{array}$ & 0 & 1 & 8 & 67 & 24 & 4,14 & Tinggi \\
\hline $\begin{array}{l}\text { Menurut Saya proses pembelian } \\
\text { makanan cepat saji hemat waktu. }\end{array}$ & 0 & 3 & 34 & 55 & 8 & 3,68 & Tinggi \\
\hline $\begin{array}{l}\text { Menurut Saya dengan membeli } \\
\text { makanan cepat saji dapat } \\
\text { menaikkan gengsi Saya. }\end{array}$ & 1 & 14 & 51 & 26 & 8 & 3,26 & $\begin{array}{l}\text { Cukup } \\
\text { Tinggi }\end{array}$ \\
\hline Rata - rata & & & & & & 3,77 & Tinggi \\
\hline \multicolumn{8}{|l|}{ Persepsi risiko } \\
\hline $\begin{array}{l}\text { Menurut Saya mengonsumsi } \\
\text { makanan cepat saji menyebabkan } \\
\text { obesitas (kelebihan lemak). }\end{array}$ & 0 & 10 & 30 & 33 & 27 & 3,77 & Tinggi \\
\hline $\begin{array}{l}\text { Menurut Saya mengonsumsi } \\
\text { makanan cepat saji menyebabkan } \\
\text { diabetes (kadar gula dalam tubuh } \\
\text { tinggi). }\end{array}$ & 0 & 10 & 43 & 23 & 24 & 3,61 & Tinggi \\
\hline $\begin{array}{l}\text { Menurut Saya harga makanan } \\
\text { cepat saji tidak sesuai dengan } \\
\text { manfaat yang diberikan. }\end{array}$ & 2 & 18 & 39 & 19 & 22 & 3,41 & Tinggi \\
\hline Rata - rata & & & & & & 3,60 & Tinggi \\
\hline \multicolumn{8}{|l|}{ Sikap } \\
\hline $\begin{array}{l}\text { Menurut Saya membeli makanan } \\
\text { cepat saji adalah keputusan yang } \\
\text { rasional. }\end{array}$ & 1 & 9 & 43 & 41 & 6 & 3,42 & Baik \\
\hline $\begin{array}{l}\text { Saya suka mengonsumsi makanan } \\
\text { cepat saji. }\end{array}$ & 2 & 10 & 43 & 36 & 9 & 3,40 & $\begin{array}{l}\text { Cukup } \\
\text { Baik }\end{array}$ \\
\hline $\begin{array}{l}\text { Saya merasa gembira dapat } \\
\text { mengonsumsi makanan cepat saji. }\end{array}$ & 4 & 16 & 52 & 19 & 9 & 3,13 & $\begin{array}{l}\text { Cukup } \\
\text { Baik }\end{array}$ \\
\hline Rata - rata & & & & & & 3,32 & $\underset{\text { Baik }}{\text { Cukup }}$ \\
\hline \multicolumn{8}{|l|}{ Niat membeli kembali } \\
\hline $\begin{array}{l}\text { Saya ingin membeli makanan cepat } \\
\text { saji lagi. }\end{array}$ & 1 & 3 & 47 & 38 & 11 & 3,55 & Tinggi \\
\hline $\begin{array}{l}\text { Jika ada variasi baru dari makanan } \\
\text { cepat saji di masa depan, Saya akan } \\
\text { membelinya }\end{array}$ & 0 & 5 & 49 & 35 & 11 & 3,52 & Tinggi \\
\hline $\begin{array}{l}\text { Saya akan merekomendasikan } \\
\text { makanan cepat saji kepada kerabat } \\
\text { Saya. }\end{array}$ & 1 & 13 & 49 & 30 & 7 & 3,29 & $\begin{array}{l}\text { Cukup } \\
\text { Tinggi }\end{array}$ \\
\hline Rata - rata & & & & & & $\mathbf{3 , 4 5}$ & Tinggi \\
\hline
\end{tabular}

Sumber: Data primer diolah, 2019

Pada uji model pengukuran (outer model) terdiri dari uji convergent validity, discriminat validity dengan menggunakan cross loading, discriminat validity 
dengan menggunakan akar kuadrat AVE dan korelasi variabel laten dan composite reliability. Gambar 2. menunjukkan hasil uji model pengukuran pada penelitian ini. Tabel 7. menampilkan kriteria yang harus dipenuhi dalam uji model pengukuran (outer model).

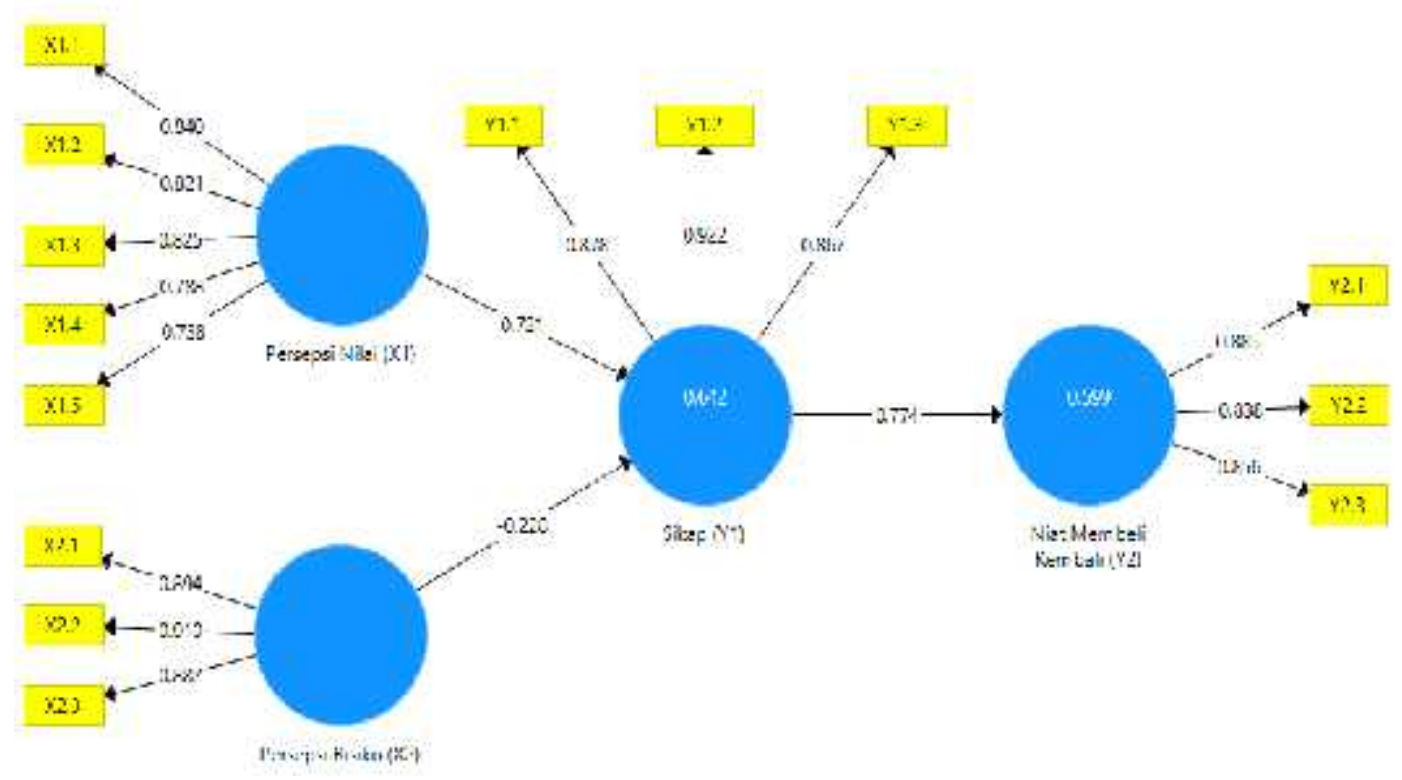

Gambar 2. Model Pengukuran (Outer Model)

Sumber: Data primer diolah, 2019

Tabel 7.

Kriteria Pengujian Model Pengukuran (Outer Model)

\begin{tabular}{ccc}
\hline & Parameter & Rule of Thumbs \\
\hline Uji Validitas & Convergent Validity & Lebih dari 0,7 \\
& Cross loading & Lebih dari 0,5 \\
& AVE & Lebih dari 0,5 \\
Uji Reliabilitas & Cronbach's alpha & Lebih dari 0,7 \\
& Composite reliability & Lebih dari 0,7 \\
\hline
\end{tabular}

Sumber: Abdillah dan Jogiyanto (2015:196)

Tabel 8. menampilkan hasil dari uji convergent validity, semua nilai pada uji validitas convergent lebih besar dari 0,7, dapat dinyatakan bahwa data dalam penelitian ini valid. Berdasarkan tabel 9, semua nilai cross loading setiap indikator pada masing - masing variabel lebih besar dari 0,5 dan juga lebih besar dari nilai cross loading variabel lain, dapat dinyatakan bahwa data dalam penelitian ini valid. Tabel 10 menampilkan hasil uji discriminant validity menggunakan akar kuadrat AVE, semua nilai AVE validitas confergent lebih besar dari 0,5, dapat dinyatakan bahwa data dalam penelitian ini valid. Tabel 11 . menampilkan hasil uji composite reliability, semua nilai composite reliability pada masing - masing variabel lebih besar dari 0,7 , dapat dinyatakan bahwa data dalam penelitian reliabel. Selain composite reliability, untuk melihat kosistensi internal suatu alat ukur dapat dilihat melalui cronbach's alpha. Variabel dinyatakan reliabel jika nilai cronbach's al pha $\geq 0,7$ 
Tabel 8.

Hasil Uji Validitas Convergent Validity

\begin{tabular}{ccccc}
\hline & $\begin{array}{c}\text { Persepsi Nilai } \\
\text { (X1) }\end{array}$ & $\begin{array}{c}\text { Persepsi Risiko } \\
\text { (X2) }\end{array}$ & Sikap (Y1) & $\begin{array}{c}\text { Niat Membeli Kembali } \\
\text { (Y2) }\end{array}$ \\
\hline X1.1 & 0.840 & & & \\
X1.2 & 0.821 & & & \\
X1.3 & 0.825 & & & \\
X1.4 & 0.788 & & & \\
X1.5 & 0.738 & & & \\
X2.1 & & 0.894 & & \\
X2.2 & & 0.910 & 0.878 & \\
X2.3 & & 0.887 & 0.922 & \\
Y1.1 & & & 0.867 & \\
Y1.2 & & & & 0.885 \\
Y1.3 & & & & 0.838 \\
Y2.1 & & & & \\
Y2.2 & & & & \\
Y2.3 & & &
\end{tabular}

Tabel 9.

Hasil Uji Validitas Discriminant Cross Loading

\begin{tabular}{lcccc}
\hline & $\begin{array}{c}\text { Persepsi } \\
\text { Nilai (X1) }\end{array}$ & Persepsi Risiko (X2) & Sikap (Y1) & $\begin{array}{c}\text { Niat Membeli } \\
\text { Kembali (Y2) }\end{array}$ \\
\hline X1.1 & $\mathbf{0 . 8 4}$ & -0.167 & 0.664 & 0.678 \\
X1.2 & $\mathbf{0 . 8 2 1}$ & -0.118 & 0.586 & 0.626 \\
X1.3 & $\mathbf{0 . 8 2 5}$ & -0.306 & 0.663 & 0.612 \\
X1.4 & $\mathbf{0 . 7 8 8}$ & -0.068 & 0.566 & 0.519 \\
X1.5 & $\mathbf{0 . 7 3 8}$ & -0.185 & 0.601 & 0.526 \\
X2.1 & -0.161 & $\mathbf{0 . 8 9 4}$ & -0.302 & -0.323 \\
X2.2 & -0.154 & $\mathbf{0 . 9 1}$ & -0.274 & -0.326 \\
X2.3 & -0.242 & $\mathbf{0 . 8 8 7}$ & -0.418 & -0.427 \\
Y1.1 & 0.668 & -0.347 & $\mathbf{0 . 8 7 8}$ & 0.684 \\
Y1.2 & 0.7 & -0.399 & $\mathbf{0 . 9 2 2}$ & 0.712 \\
Y1.3 & 0.687 & -0.273 & $\mathbf{0 . 8 6 7}$ & 0.667 \\
Y2.1 & 0.686 & -0.45 & 0.773 & $\mathbf{0 . 8 8 5}$ \\
Y2.2 & 0.639 & -0.281 & 0.587 & $\mathbf{0 . 8 3 8}$ \\
Y2.3 & 0.577 & -0.301 & 0.609 & $\mathbf{0 . 8 5 6}$ \\
\hline
\end{tabular}

Sumber: Data primer diolah, 2019

Tabel 10.

Hasil Uji Validitas Convergent AVE

\begin{tabular}{lc}
\hline & Rata-rata Varians Diekstrak (AVE) \\
\hline Persepsi nilai (X1) & 0.645 \\
Persepsi risiko (X2) & 0.805 \\
Sikap (Y1) & 0.791 \\
Niat membeli kembali (Y2) & 0.739 \\
\hline
\end{tabular}

Sumber: Data primer diolah, 2019

Selain composite reliability, untuk melihat kosistensi internal suatu alat ukur dapat dilihat melalui cronbach's alpha. Variabel dinyatakan reliabel jika nilai cronbach's alpha $\geq 0,7$ (Abdillah dan Jogiyanto, 2015:196). Tabel 12. 
menampilkan hasil uji reliabilitas yang diukur melalui cronbach's alpha. Berdasarkan Tabel 12. dapat dilihat bahwa semua nilai Cronbach's al pha pada masing - masing variabel lebih besar dari 0,7, dapat dinyatakan bahwa data dalam penelitian ini reliabel.

Tabel 11.

Hasil Uji Composite Reliability

\begin{tabular}{lc}
\hline & Reliabilitas Komposit \\
\hline Persepsi nilai (X1) & 0.901 \\
Persepsi risiko (X2) & 0.925 \\
Sikap (Y1) & 0.919 \\
Niat membeli kembali & 0.895 \\
\hline
\end{tabular}

Sumber: Data primer diolah, 2019

Tabel 12.

Hasil Uji Reliabilitas Crombach'sAlpha

\begin{tabular}{lc}
\hline & Cronbach's Alpha \\
\hline Persepsi nilai (X1) & 0.862 \\
Persepsi risiko (X2) & 0.882 \\
Sikap (Y1) & 0.868 \\
Niat membeli kembali (Y2) & 0.825 \\
\hline
\end{tabular}

Sumber: Data primer diolah, 2019

Pengujian model struktural (inner model) dilakukan untuk menguji hubungan variabel laten atau hipotesis, yang dilihat dari $R$-square dan $Q$-square. Gambar 3 menunjukkan hasil uji inner model pada penelitian ini.

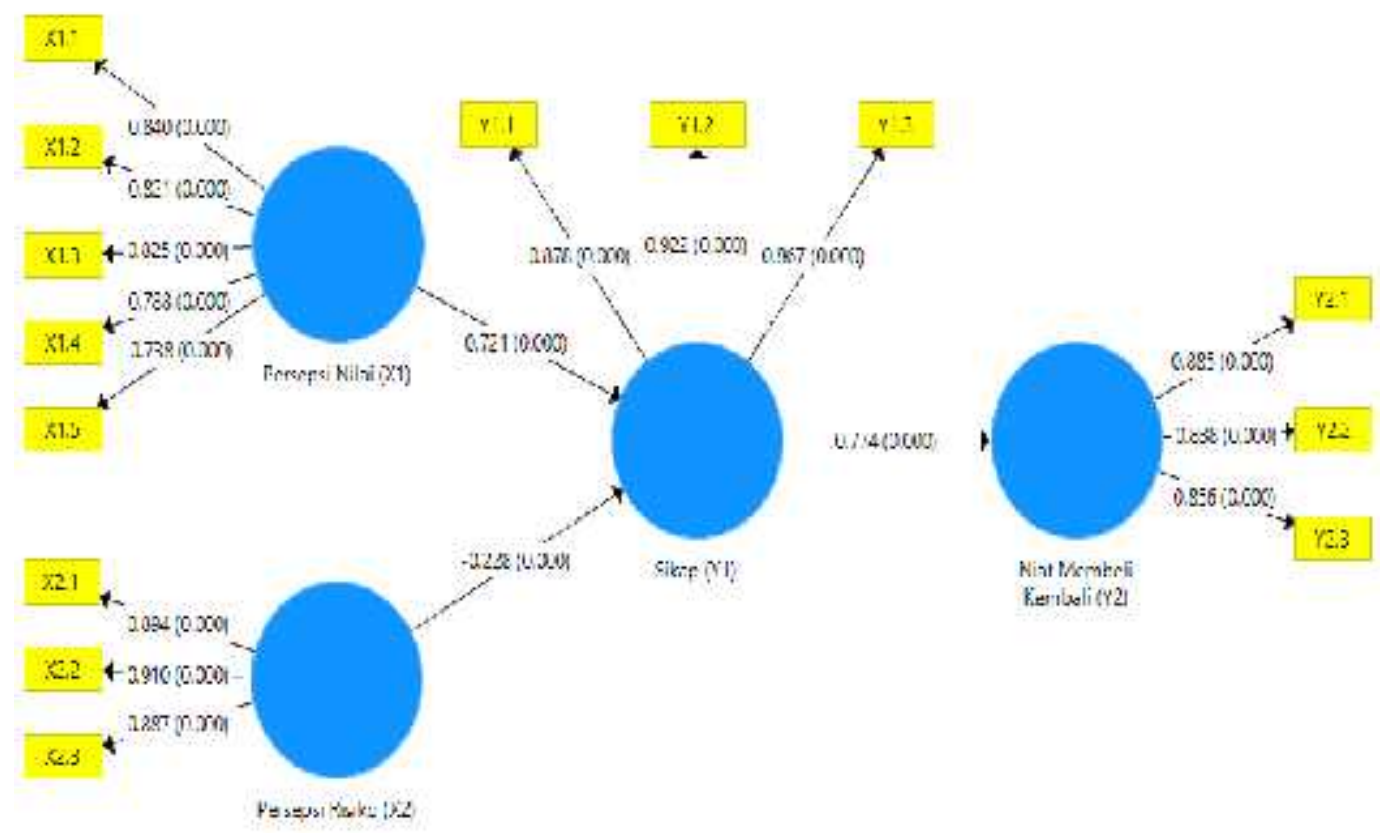

Gambar 3. Model Struktural (Inner Model)

Sumber: Data primer diolah, 2019 
Tabel 13.

Hasil Uji R-square

\begin{tabular}{lcc}
\hline & R Square & Adjusted R Square \\
\hline Sikap (Y1) & 0.642 & 0.635 \\
Niat membeli kembali (Y2) & 0.599 & 0.594 \\
\hline
\end{tabular}

Sumber: Data primer diolah, 2019

Nilai $R$-square $\left(\mathrm{R}^{2}\right)$ berfungsi untuk mengetahui seberapa besar (\%) pengaruh variabel independen terhadap variabel dependennya, rentang nilai $R$ square adalah 0 -1. Tabel 13 menunjukkan hasil uji $R$ - square pada penelitian ini. Nilai $R$-square untuk variabel persepsi nilai dan persepsi risiko terhadap sikap sebesar 0,642 atau 64,2\% dimana dapat dikatakan pengaruhnya kuat. Nilai $R$ square untuk variabel persepsi nilai dan persepsi risiko terhadap niat membeli kembali sebesar 0,599 atau 59,9\% dapat dikatakan cukup kuat. Pengujian inner model dilakukan dengan melihat nilai $Q$-square yang merupakan uji goodness of fit model.

$\mathrm{Q}^{2}=1-\left[\left(1-\mathrm{R}_{1}^{2}\right)\left(1-\mathrm{R}_{2}^{2}\right)\right]$

$\mathrm{Q}^{2}=1-\left[\left(1-0,599^{2}\right)\left(1-0,642^{2}\right)\right]$

$\mathrm{Q}^{2}=1-[(1-359)(1-412)]$

$\mathrm{Q}^{2}=1-[(0,641)(0,588)]$

$\mathrm{Q}^{2}=1-(0,377)$

$\mathrm{Q}^{2}=0,623$

Berdasarkan perhitungan, diperoleh nilai $Q$-square sebesar 0,623 lebih dari 0 , sehingga dapat disimpulkan bahwa model dalam penelitian ini mempunyai nilai prediktif yang relevan dan layak digunakan.

Tabel 14.

Hasil Uji Pengaruh Langsung

\begin{tabular}{|c|c|c|c|c|c|}
\hline & $\begin{array}{l}\text { Sampel } \\
\text { Asli (O) }\end{array}$ & $\begin{array}{c}\text { Sample } \\
\text { Mean (M) }\end{array}$ & $\begin{array}{l}\text { Standar } \\
\text { Deviasi } \\
\text { (STDEV) }\end{array}$ & $\begin{array}{l}\text { T Statistik } \\
\text { (O/STDEV) }\end{array}$ & P Values \\
\hline $\begin{array}{l}\text { Persepsi Nilai (X1) -> } \\
\text { Sikap (Y1) }\end{array}$ & 0.721 & 0.719 & 0.042 & 17.223 & 0.000 \\
\hline $\begin{array}{l}\text { Persepsi Risiko (X2) - } \\
>\text { Sikap (Y1) }\end{array}$ & -0.228 & -0.231 & 0.057 & 4.007 & 0.000 \\
\hline $\begin{array}{l}\text { Sikap (Y1) -> Niat } \\
\text { Membeli Kembali } \\
\text { (Y2) }\end{array}$ & 0.774 & 0.774 & 0.060 & 12.807 & 0.000 \\
\hline
\end{tabular}

Sumber: Data primer diolah, 2019

Tabel 14. menunjukkan hasil dari pengujian hipotesis. Nilai $p$-value variabel persepsi nilai terhadap sikap sebesar 0,000 lebih kecil dari 0,05 , ini berarti persepsi nilai berpengaruh terhadap sikap. Nilai beta positif 0,721 menunjukkan bahwa pengaruh persepsi nilai terhadap sikap adalah positif. Nilai t-statistik $>$ ttabel $(17,223>1,985)$, ini berarti pengaruh persepsi nilai terhadap sikap 
signifikan. Dapat disimpulkan bahwa pengaruh persepsi nilai dan sikap adalah positif signifikan. Hal ini berarti hipotesis pertama $\left(\mathrm{H}_{1}\right)$ diterima. Semakin banyak manfat dari makanan yang dirasakan konsumen baik dari segi kelezatan, tampilan visual, variasi jenis maupun keceptan penyajian dan tingkat gengsi yang ditawarkan, maka konsumen akan semakin menyukai makanan cepat saji.

Pada penelitian ini, konsumen merasa selain dapat menghemat waktu, makanan cepat saji memiliki rasa yang lezat dan tampilan yang menarik. Makanan cepat saji disajikan dengan pilihan bahan berwarna - warni mulai dari merah, hijau dan warna lainnya yang ditata dengan tujuan menggugah selera konsumen untuk mencobanya. Restoran cepat saji melakukan inovasi pada produk makanan cepat sajinya dengan cara menambah komponen yang disukai konsumennya, seperti ditawarkannya nasi, sambal dan beberapa menu dengan keju untuk konsumen Indonesia. Upaya tersebut memperbanyak varian makanan cepat saji sehingga dapat memenuhi selera konsumen yang berbeda - beda. Beberapa konsumen menilai bahwa dengan membeli dan mengonsumsi makanan cepat saji dapat meingkatkan gengsi mereka. Banyak merek terkenal dari restoran cepat saji yang beroperasi secara global berasal dari negara maju seperti Amerika dan harga yang ditawarkan untuk produknya setara dengan harga di negara asal merek tersebut. Hal tersebut menciptakan kesan bahwa konsumen makanan cepat saji memiliki gaya hidup dan pergaulan seperti layaknya orang - orang di negara maju. Faktor - faktor tersebut merupakan manfaat yang jika semakin baik akan membuat konsumen semakin menyukai makanan cepat saji.

Hasil ini sejalan dengan hasil penelitian Hassan et al. (2016) pada makanan yang dimodifikasi secara genetik, bahwa persepsi nilai memengaruhi sikap secara positif. Semakin besar manfaat yang dirasakan konsumen terhadap suatu produk bagi kehidupannya, semakin baik pula sikap mereka pada produk tersebut. Menurut Hermawan \& Haryanto (2013) yang meneliti mengenai niat beli salah satu merk sepatu, sikap konsumen terbentuk dari pertimbangan atas persepsi nilai. Penelitian Zhu et al. (2017) pada aplikasi mobile menemukan bahwa persepsi nilai berpengaruh kuat dan positif terhadap sikap. Mao \& Lyu (2017) yang meneliti perilaku konsumen AirBnb menemukan bahwa persepsi nilai memengaruhi sikap secara positif. Ketika konsumen memilih suatu produk, mereka merasakan kontribusi atau keunikan tersendiri yang menentukan sikap mereka pada produk tersebut. Terlihat bahwa persepsi nilai memiliki pengaruh yang sama terhadap sikap baik pada barang seperti makanan maupun aplikasi akomodasi online yang menawarkan jasa.

Nilai $p$-value variabel persepsi risiko terhadap sikap sebesar 0,000 lebih kecil dari 0,05, ini berarti persepsi nilai berpengaruh terhadap sikap. Nilai beta 0,228 menunjukkan bahwa pengaruh persepsi risiko terhadap sikap adalah negatif. Nilai t-statistik > t-tabel $(4,007>1,985)$, ini berarti pengaruh persepsi nilai terhadap sikap signifikan. Dapat disimpulkan bahwa pengaruh persepsi risiko terhadap sikap adalah negatif signifikan. Hal ini berarti hipotesis kedua $\left(\mathrm{H}_{2}\right)$ diterima. Semakin tinggi risiko yang mungkin terjadi ketika membeli dan mengonsumsi makanan cepat saji, maka rasa suka konsumen akan semakin menurun terhadapnya. 
Berdasarkan jawaban responden pada kuesioner penelitian ini, konsumen makanan cepat saji dihadapkan dengan risiko kesehatan dan juga finansial yang membuat mereka merasa tidak terlalu senang akan keputusannya untuk membeli dan mengonsumsi makanan cepat saji terlepas dari manfaat yang mereka rasakan. Obesitas adalah risiko terbesar yang disadari konsumen dari makanan cepat saji pada penelitian ini, diikuti dengan diabetes. Konsumen tidak terlalu senang dengan kenyataan bahwa mereka mengeluarkan uang lebih banyak untuk makanan cepat saji dengan risiko kesehatan tersebut. Risiko - risiko tersebut menurunkan rasa suka konsumen terhadap makanan cepat saji.

Hasil ini sejalan dengan hasil penelitian Sharma \& Kalyandurgmath (2016) mengenai makanan hasil rekayasa genetika yang mendapatkan hasil bahwa persepsi risiko berpengaruh negatif terhadap sikap. Ketika konsumen menyadari risiko dari mengonsumsi ataupun membeli suatu produk, rasa suka mereka terhadap produk tersebut akan berkurang. Penelitian pada makanan jalanan (street food) yang dilakukan oleh Choi et al. (2013) juga menemukan persepsi risiko berpengaruh negatif terhadap sikap, dimana setiap risiko yang diketahui oleh konsumen dari keputusan membeli dan mengonsumsi produk, akan sangat menentukan sikap mereka terhadap suatu produk. Hubungan persepsi risiko yang memengaruhi sikap secara negatif juga ditunjukkan oleh penelitian Mao \& Lyu (2017) pada aplikasi akomodasi online AirBnB, dimana konsumen memprediksi risiko - risiko yang mungkin diterima sehingga hal tersebut memengaruhi sikap mereka. Hal ini juga didukung oleh penelitian Liou et al. (2014) pada pengguna $T V$ cable yang menemukan persepsi risiko berpengaruh negatif terhadap sikap. Risiko menentukan sikap dan keputusan konsumen terhadap suatu produk. Berdasarkan hasil penelitian ini dan beberapa penelitian sebelumnya dapat dilihat bahwa persepsi risiko memiliki pengaruh yang negatif pada objek yang berbeda yaitu makanan, aplikasi akomodasi online dan layanan TV cable.

Nilai $p$-value variabel sikap terhadap niat membeli kembali sebesar 0,000 lebih kecil dari 0,05, ini berarti sikap berpengaruh terhadap niat membeli kembali. Nilai beta positif 0,774 menunjukkan bahwa sikap terhadap niat membeli kembali adalah positif. Nilai t-statistik > t-tabel $(12,807>1,985)$, ini berarti pengaruh sikap terhadap niat membeli kembali signifikan. Dapat disimpulkan bahwa pengaruh sikap terhadap niat membeli kembali adalah positif signifikan. Hal ini berarti hipotesis ketiga $\left(\mathrm{H}_{3}\right)$ diterima. Semakin baik sikap konsumen terhadap makanan cepat saji, maka niat untuk membeli kembali makanan cepat saji akan semakin tinggi.

Berdasarkan hasil survei, konsumen merasa bahwa keputusan membeli dan mengonsumsi makanan cepat saji tergolong rasional dan membuat mereka cukup menyukai makanan cepat saji. Konsumen cukup senang dengan manfaat dari makanan cepat saji yang dapat menghemat waktu mereka untuk bersantap di tengah kesibukan yang padat. Variasi, tampilan, rasa dan gengsi yang ditawarkan makanan cepat saji juga menjadi faktor yang membuat mereka menyukai makanan cepat saji. Risiko yang dirasakan konsumen juga mempengaruhi sikap konsumen terhadap makanan cepat saji dimana mereka tidak bisa sepenuhnya menyukai makanan cepat saji. Rasa suka konsumen yang semakin tinggi terhadap 
makanan cepat saji memperbesar niat konsumen untuk membeli kembali makanan cepat saji.

Hasil ini sejalan dengan hasil penelitian Kusuma \& Marta (2014) pada mie instan Sarimi yang mendapatkan hasil bahwa sikap memengaruhi niat membeli kembali secara positif. Penelitian Ahmadi et al. (2010) pada produk olahan daging beku juga memperoleh hasil sikap berpengaruh positif. Sikap menentukan keputusan konsumen untuk membeli lagi atau tidak. Hubungan sikap yang memengaruhi niat membeli kembali secara positif juga diperoleh pada penelitian Mao \& Lyu (2017) pada pengguna AirBnB. Hal ini juga didukung oleh penelitian Dewi \& Ardani (2016) yang memperoleh hasil yaitu sikap berpengaruh positif terhadap niat membeli kembali produk fashion. Penelitian Yudha \& Sumiati (2015) pada niat membeli kembali polis asuransi kerugian, turut mendukung hasil bahwa sikap berpengaruh positif terhadap niat membeli kembali. Sikap yang positif yang dimiliki konsumen setelah mempertimbangkan manfaat dari suatu produk, merupakan salah satu penyebab adanya niat untuk membeli produk itu kembali di masa depan. Terlihat bahwa tidak hanya pada makanan, sikap juga memiliki pengaruh yang positif terhadap niat membeli kembali ketika diuji pada objek seperti polis asuransi, produk fashion dan juga aplikasi akomodasi online. Temuan pada penelitian ini dan beberapa penelitian terdahulu tidak bertentangan dengan teori yang diacu yaitu Theory of Reasoned Action yang menyatakan bahwa sikap memengaruhi perilaku konsumen yang salah satunya adalah niat untuk membeli kembali.

Penelitian ini menguji hubungan langsung dari persepsi nilai terhadap sikap, persepsi risiko terhadap sikap, dan hubungan sikap terhadap niat membeli kembali. Lokasi dari responden yang diteliti adalah Indonesia. Indikator indikator untuk mendeskripsikan variabel disesuaikan dengan budaya, keadaan ekonomi dan pandangan masyarakat Indonesia terhadap makanan cepat saji yang ditawarkan restoran cepat saji di Indonesia. Tidak menutup kemungkinan bahwa temuan pada penelitian ini akan berbeda dengan temuan pada penelitian yang memiliki variabel yang sama namun berbeda dari segi subyek dan obyek, waktu, budaya, ekonomi atau faktor lainnya. Penelitian selanjutnya diharapkan dapat menguji dari sudut pandang yang berbeda maupun dan juga menguji peran sikap dalam memediasi pengaruh persepsi nilai dan persepsi risiko terhadap niat membeli kembali.

\section{SIMPULAN}

Berdasarkan hasil penelitian ini dapat disimpulkan bahwa persepsi nilai berpengaruh positif terhadap sikap. Semakin besar manfaat yang dirasakan konsumen dari makanan cepat saji, maka konsumen akan semakin suka terhadap makanan cepat saji. Persepsi risiko berpengaruh negatif terhadap sikap. Hal ini berarti semakin besar risiko yang dirasakan konsumen dari makanan cepat saji, maka rasa suka konsumen terhadap makanan cepat saji akan semakin berkurang. Sikap berpengaruh positif terhadap niat membeli kembali. Semakin konsumen menyukai makanan cepat saji, maka niat konsumen untuk membeli lagi makanan cepat saji menjadi semakin tinggi. 
Makanan cepat saji dapat membantu menghemat waktu yang diperlukan untuk bersantap namun di sisi lain juga memiliki dampak buruk bagi kesehatan jika dikonsumsi secara berlebihan. Restoran cepat saji diharapkan mulai memerhatikan tingkat kesehatan dari makanan cepat saji yang mereka tawarkan. Kualitas makanan cepat saji dari segi kesehatan dapat dijaga dengan selalu memastikan bahan yang digunakan segar, bersih, sehat dan juga proses produksi yang dilakukan tidak menimbulkan zat - zat yang dapat membahayakan kesehatan. Langkah tersebut membuat harga makanan cepat saji sebanding dengan manfaat yang dirasakan konsumen. Secara tidak langsung, restoran cepat saji membantu meminimalisir risiko yang dihadapi konsumen cepat saji.

Kekhawatiran konsumen akan berkurang sehingga mereka merasa lebih nyaman mengonsumsi makanan cepat saji. Hal tersebut dapat meningkatkan rasa suka konsumen, selain itu konsumen akan lebih percaya diri ketika membeli dan mengonsumsi makanan cepat saji, maupun untuk merekomendasikannya kepada kerabat mereka atau membeli lagi di masa depan. Keterbatasan pada penelitian ini dapat menjadi salah satu pertimbangan pada penelitian di masa depan baik untuk menguji kembali hasil yang telah didapat serta mengetahui bagaimana hasil dari hubungan - hubungan yang diuji pada penelitian ini jika digunakan pada kondisi yang berbeda.

\section{REFERENSI}

Abdillah, W., \& Jogiyanto. (2015). Partial Least Square (PLS) - Alternatif Structural Equation Modeling (SEM) Dalam Penelitian Bisnis. Yogyakarta: Penerbit Andi.

Afifah, L. P., Suyatno, Aruben, R., \& Kartini, A. (2017). Faktor - Faktor yang Berhubungan Dengan Konsumsi Fast Food pada Remaja Obesitas di SMA Theresiana 1 Semarang Tahun 2017. Jurnal Kesehatan Masyarakat (EJournal), 5(4), 2356 - 3346.

Ahmadi, A. Y., Syahlani, S. P., \& Haryadi, F. T. (2010). Pengaruh Persepsi Konsumen Terhadap Atribut Produk Pada Sikap Terhadap Produk Dan Niat Pembelian Ulang: Studi Empirik Pengambilan Keputusan pada Kategori Produk Daging Olahan Beku. Buletin Peternakan, 34(2), 131 - 137. https://doi.org/10.21059/buletinpeternak.v34i2.99

Anwar, C. R. (2016). Fast Food: Gaya Hidup dan Promosi Makanan Siap Saji. Jurnal Etnografi Indonesia, $1(2), \quad 54 \quad-\quad 65$. https://doi.org/http://dx.doi.org/10.31947/etnosia.v1i2.1615

Badan Pusat Statistik. (2018). Rata - rata Upah/Gaji Bersih Sebulan Buruh/Karyawan/Pegawai Menurut Kelompok Umur dan Jenis Pekerjaan (Rupiah) $2017 . \quad$ Retrieved from https://www.bps.go.id/statictable/2018/03/13/1994/rata-rata-upah-gajibersih sebulan-buruh-karyawan-pegawai-menurut-kelompok-umur-danjenis-pekerjaan--rupiah---2017.html 
Bashir, I., \& Madhavaiah, C. (2015). Consumer Sikap and Behavioral Intention Towards Internet Banking Adoption in India. Journal of Indian Business Research, 7(1), 67-102. https://doi.org/10.1108/JIBR-02-2014-0013

Bonita, I. A., \& Fitranti, D. Y. (2017). Konsumsi Fast Food dan Aktivitas Fisik Sebagai Faktor Risiko Kejadian Overweight Pada Remaja Stunting SMP. Journal of Nutrition College, 6(1), 52 - 60.

Choi, J., Lee, A., \& Ok, C. (2013). The Effect Of Consumers' Perceived Risk and Benefit On Attitude And Behavioral Intention: A Study of Street Food. Journal of Travel \& Tourism Marketing, 30(3), 222 - 237. https://doi.org/dx.doi.org/10.1080/10548408.2013.774916

Damopolii, W., Mayulu, N., \& Masi, G. (2013). Hubungan Konsumsi Fast Food Dengan Kejadian Obesitas Pada Anak SD Di Kota Manado. E-Journal Keperawatan, 1(1), 1-7.

Dewi, N. P. R. A., \& Ardani, I. G. A. K. S. (2016). Pengaruh Sikap, Norma Subyektif Terhadap Niat Beli Ulang Produk Fashion Via Online di Kota Denpasar. E-Jurnal Manajemen Unud, 5(1), 650 - 677.

Evan, W. J. ., \& Candrawati, E. (2017). Hubungan Antara Pola Makan Dengan Kejadian Obesitas Pada Mahasiswa Di Universitas Tribhuwana Tunggadewi Malang. Nursing News, 2(3), $708-717$.

Ghozali, I. (2016). Aplikasi Analisis Multivariete Dengan Program IBM SPSS 23 (Edisi Delapan). Semarang: Badan Penerbit Universitas Diponegoro.

Goh, S. ., Jiang, N., Hak, M. F. ., \& Tee, P. . (2016). Determinants of Smartphone Repeat Purchase Intention Among Malaysians: A Moderation Role of Social Influence and A Mediating Effect of Consumer Satisfaction. International Review of Management \& Marketing, 6(4), 993-1004.

Hanum, T. S. L., Dewi, A. P., \& Erwin. (2015). Hubungan Antara Pengetahuan dan Kebiasaan Mengkonsumsi Fast Food Dengan Status Gizi Pada Remaja. Jurnal Online Mahasiswa Program Studi Keperawatan Universitas Riau, 2(1), $750-758$.

Hardian. (2018). Pengin Menu Fast Food Tapi Duit Mepet, Ke Sini Aja. Retrieved from https://www.moneysmart.id/pengin-menu-fast-food-duit-mepet-siniaja

Hassan, S. . (2017). The Role of Customer Innovativeness in The New Products Adoption Intentions: An Empirical Study on Mobile Phone Customers of The Egyptian Universities Students. International Business Research, 10(4), 117-130. https://doi.org/10.5539/ibr.v10 n 4 p 117

Hassan, S. H., Kua, J. S. B., \& Harun, H. (2016). Muslim Consumers' Perception and Purchase Intention Toward GM Food. International Food Research Journal, 23(2), $806-815$. 
Hazanah, S., \& Andriani, R. (2016). Dampak Pengetahuan dan Makanan Cepat Saji Terhadap Kanker Payudara Pada Wanita. Mahakam Nurshing Journal, $1(1), 27-36$.

Hermawan, H., \& Haryanto, B. (2013). Analisis Pengaruh Persepsi Prestise, Persepsi Kualitas, Persepsi Nilai, Citra Merek, Citra Negara Asal Terhadap Niat Pembelian Produk Asing Yang Dimediasi Sikap Dan Variabel Customer's Ethnocentrism Sebagai Peran Moderasi (Studi Pada Niat Pembelian Produk. Fokus Manajerial, 12(1), 23 - 40.

Joseph, A. A., Tondobala, T., \& Mononimbar, W. (2017). Sarana Kebugaran dan Relaksasi di Manado. "Arsitektur Lansekap - Sensasi Natural." Jurnal Arsitektur, 6(2), 122 - 130.

Kusuma, A. B. T., \& Marta, L. S. (2014). Pengaruh Kesadaran Merk, Sikap dan Nilai Yang Dirasa Terhadap Niat Pembelian Ulang Sarimi di Surabaya Timur. Journal of Business and Banking, 5(2), 299 - 318. https://doi.org/10.14414/jbb.v5i2.546

Liou, D. K., Hsu, L. C., \& Chih, W. H. (2014). Understanding Broadband Television Users' Continuance Intention To Use. Industrial Management \& Data Systems, 115(2), 210 - 234. https://doi.org/10.1108/IMDS-07-20140223

Mao, Z., \& Lyu, J. (2017). Why Travelers Use AirBnB Again? An Integrative Approach To Understanding Travelers' Repurchase Intention. International Journal of Contemporary Hospitality Management, 29(9), 2464 - 2482. https://doi.org/10.1108/IJCHM-08-2016-0439

Nielsen. (2016). What's In Our Food and On Our Mind: Ingredient and DiningOut Trends Around The World. New York City.

Oktarini, M. A. S., \& Wardana, I. M. (2018). Pengaruh Perceived Easy of Use dan Perceived Enjoyment Terhadap Customer Satisfaction and Repurchase Intention. Jurnal Inovasi Bisnis Dan Manajemen Indonesia, 1(2), 227 - 237.

Panthura, G. (2011). Rising To The Global Challenge: Entrepreneurship And Smes Development In Asia. The 8th SMEs in a Global Economy Conference 2011.

Petrick. (2002). Development of Multidimensional Scale For Measuring The Perceived Value of A Service. Journal of Leisure Research, 34(4), 119-134. https://doi.org/https://doi.org/10.1080/00222216.2002.11949965

Ryu, K., Lee, H. R., \& Kim, W. G. (2012). The Influence Of The Quality Of The Physical Environment, Food, And Service On Restaurant Image, Customer Perceived Value, Customer Satisfaction, And Behavioral Intentions. International Journal Of Contemporary Hospitality Management, 24(2), 200 - 232. https://doi.org/10.1108/09596111211206141

Schiffman, L. G., \& Wisenblit, J. L. (2015). Consumer Behavior (Eleventh 
Edition). Essex: Pearson.

Shahid, M. N. (2012). Work Stress and Employee Performance in Banking Sector Evidence From District Faisalabad, Pakistan. Asian Journal of Business and Management Sciences, 1(7), 38-47.

Sharma, P., \& Kalyandurgmath, K. (2016). Determinants of Buying Intention For Genetically Modified Food. International Journal of Asian School of Business Management, 9(1), 70 - 82.

Srivastava, R. K. (2014). How Differing Demographic Factors Impact Consumers' Loyalty Towards National or International Fast Food Chains: A Comparative Study In Emerging Market. British Food Journal, 177(4), 1354 - 1376. https://doi.org/10.1108/BFJ-07-2014-0230

Stone, R. N., \& Grønhaug, K. (1993). Perceived Risk: Further Considerations for the Marketing Discipline. European Journal of Marketing, 27(3), 39-50. https://doi.org/doi.org/10.1108/03090569310026637

Sugiyono. (2017). Metode Penelitian Bisnis. Bandung: Alfabeta.

Suyana, U. M. (2016). Aplikasi Analisis Kuantitatif. Denpasar: CV. Sastra Utama.

Tamulien, V. (2015). Perspective of Fast Food Consumption In Lithuania. Management Theory and Studies For Rural Business and Infrastructure Development. Scientific Journal, 35(3), 441 - 447.

Tjandra, C., Nathania, C., \& Kristanti, M. (2015). Analisa Meal Experience dan Pengaruhnya Terhadap Minat Beli Ulang Di Restoran Jepang Di Surabaya. Jurnal Hospitaliti Dan Manajemen Jasa, 3(1), 66 - 81.

Utama, S. (2015). Metode Riset untuk Bisnis dan Ekonomi. Jakarta: Erlangga.

Wang, E. S. . (2015). Effect Of Food Service-Brand Equity On ConsumerPerceived Food Value, Physical Risk, And Brand Preference. British Food Journal, 117(2), 553 - 564. https://doi.org/10.1108/BFJ-09-2013-0260

Yanuar, E. R. (2016). Survei: 52\% Orang Jakarta Jadikan Junk Food Sebagai Sarapan. Retrieved from Metro TV News website: http://rona.metrotvnews.com/read/2016/08/20/571823/survei-52-orangjakarta-jadikan-junk-food-sebagai-sarap

Yudha, E. C., \& Sumiati, F. R. (2015). Pengaruh Sikap, Norma Subyektif, Kontrol Keperilakuan, dan Kepercayaan Nasabah Terhadap Niat Membeli Kembali Polis Asuransi Kerugian (Studi Pada PT. Asuransi Jasa Indonesia (Persero) Cabang Surabaya Koporasi). Jurnal Aplikasi Manajemen, 13(4), 673 - 681.

Zheng, X., Lee, M., \& Cheung, C. M. K. (2017). Examining E-Loyalty Towards Online Shopping Platforms: The Role of Coupons Proneness and Value Consciousness. Internet Research, 27(3), $709 \quad-\quad 726$. https://doi.org/10.1108/IntR-01-2016-0002 
Ni Ketut Eugenia Shara Devi, Pengaruh Persepsi Nilai.....

Zhu, G., So, K. K. F., \& Hudson, S. (2017). Inside The Sharing Economy: Understanding Consumer Motivations Behind The Adoption of Mobile Applications. International Journal of Contemporary Hospitality Management, 29(2), 2218 - 2239. https://doi.org/10.1108/IJCHM-09-20160496 